\title{
Variation in the structure of subtidal landscapes in the NW Mediterranean Sea
}

\author{
L. Tamburello ${ }^{1, *}$, L. Benedetti-Cecchi ${ }^{1}$, G. Ghedini ${ }^{1}$, T. Alestra ${ }^{1,2}$, F. Bulleri ${ }^{1}$ \\ ${ }^{1}$ Dipartimento di Biologia, Università di Pisa, CoNISMa, Via Derna 1, 56126 Pisa, Italy \\ ${ }^{2}$ Marine Ecology Research Group, School of Biological Sciences, University of Canterbury, Private Bag 4800, Christchurch 8140,
} New Zealand

\begin{abstract}
Compounded effects of climate change and local human activities are threatening marine biodiversity worldwide. At a regional scale (10s to $100 \mathrm{~s} \mathrm{~km}$ ), comparisons among areas characterized by the prevalence of different human activities provide an insight into the effects of anthropogenic disturbances at multiple levels of ecological organization (i.e. from landscapes to assemblages). At the landscape scale (1000s m), we hypothesized that patchiness in habitat distribution and proportion of degraded assemblages would increase with increasing levels of disturbance, as a result of the decline of habitat-forming species. In addition, we hypothesized that prevailing human influences would affect the structure and variability of rocky benthic assemblages at smaller spatial scales (10s $\mathrm{cm}$ to $10 \mathrm{~s} \mathrm{~m}$ ). An extensive survey encompassing areas subjected to different human influences (i.e. from urbanized to protected areas) was carried out along the coasts of Tuscany (NW Mediterranean Sea). Seagrass beds and macroalgal canopy stands were the dominant habitats in relatively pristine areas, while macroalgal turfs and dead rhizomes of Posidonia oceanica were the most extended habitats in urbanized areas. In general, habitat fragmentation did not vary among areas subjected to different human influences. At a smaller scale $(10 \mathrm{~s} \mathrm{~cm}$ to $10 \mathrm{~s} \mathrm{~m})$, urbanization favored dominance by opportunistic species and promoted biotic homogenization. Our study shows that regional variations in the composition of landscapes and assemblages can be predicted on the basis of prevailing human activities. Our results also suggest that variations in landscape composition could be an effective descriptor of the effects of multiple human stressors in marine environments.
\end{abstract}

KEY WORDS: Habitat degradation - Urbanization - Benthic assemblage - Biotic homogenization · Landscape $\cdot$ Fragmentation $\cdot$ Marine protected area $\cdot$ MPA $\cdot$ Mediterranean

\section{INTRODUCTION}

Compounded effects of global climate change and local human activities, such as coastal development, organic and inorganic pollution, and overfishing, pose severe threats to marine biodiversity (Gray 1997). Recent efforts to map the spatial distribution of human activities have suggested that the number and severity of overlapping threats can vary locally in coastal areas (Halpern et al. 2008). Thus, prevailing environmental conditions (i.e. climate, geology) and human activities (either negative or positive, such as the establishment of marine protected areas, MPAs) set the regional scenario within which factors operating at finer scales, from the seascape to the habitat, down to the community, operate to regulate patterns of abundance and distribution of marine organisms. Nonetheless, little effort has been made, over regional scales, to assess variation at different levels of ecological organization among areas characterized by the prevalence of different human activities. 
Shallow rocky reefs support highly diverse and productive assemblages that are among the most susceptible to human influences (Halpern et al. 2007). According to the regional geomorphology, rocky reefs can be found in proximity to the mainland or in off-shore waters (i.e. shoals or islands). Thus, they can be exposed to different environmental conditions (e.g. currents, salinity, riverine inputs) and human pressures that vary in both nature and intensity. For instance, coastal reefs are more likely to be exposed to degraded environmental conditions (i.e. inputs of sediments, nutrients and pollutants, development of coastal infrastructures) than off-shore or island reefs. On the other hand, activities such as trawling, recreational boating, diving, and angling can be widespread or more common on reefs relatively far from major human conglomerates.

At the community scale, human influences can alter the richness and relative abundance of species in benthic assemblages (Claudet \& Fraschetti 2010), increase the susceptibility to invasion by introduced species (Bulleri et al. 2010), and reduce food-web complexity (Guidetti 2006). In addition, anthropogenic stressors can either increase (Warwick \& Clarke 1993) or reduce (Chapman et al. 1995) the spatial variability of natural communities.

At the landscape scale, human influences can cause the loss or fragmentation of habitats (Airoldi \& Beck 2007). For instance, the regression of canopyforming macroalgal stands or seagrass beds and the consequent expansion of alternative habitats (e.g. algal turfs or dead rhizomes of Posidonia oceanica [hereafter also referred to as matte], respectively) have been documented in urban areas worldwide (Benedetti-Cecchi et al. 2001, Balestri et al. 2004, Mangialajo et al. 2008, Gorman \& Connell 2009). Thus, the ultimate effect of the regression of habitatforming species highly susceptible to altered environmental conditions is often the formation of mosaics of habitats. Several studies have attempted to elucidate the causal mechanisms which promote switches between alternative habitat pairs (i.e. canopy-forming macroalgae versus algal turfs: Bulleri et al. 2002a, Mangialajo et al. 2008; erect macroalgae versus encrusting coralline barrens: Bulleri et al. 2002b, Guidetti 2006; seagrass beds versus dead rhizome matte: Balestri et al. 2004).

Fragmentation and switches to alternative habitats can be driven by physical (e.g. sedimentation, hydrologic alterations, dredging, or anchoring), chemical (eutrophication, inorganic pollution), or biological disturbances (overfishing, biological invasions) that trigger a complex process of habitat degradation or loss and the consequent switch in habitat structure and patch quality (for a comprehensive list of causal mechanisms see Boström et al. 2011). However, despite the growing interest in coastal biogenic habitats like seagrass meadows, salt marshes, and coral reefs, alterations in the structure of landscapes have been rarely investigated in the marine realm (Boström et al. 2011). In particular, no study has, to the best of our knowledge, examined how the relative proportion of different habitats and their spatial configuration (i.e. size and patchiness) vary among areas subjected to different levels of human influence.

Here we explored the effects of multiple human activities at a regional scale, encompassing both an along-shore and an off-shore gradient of disturbance. First, we evaluated how the relative availability and spatial configuration of habitats vary among areas subjected to decreasing levels of human pressure, by selecting study locations in urban and extraurban settings, off-shore shoals, and in MPAs established off islands. In particular, we hypothesized that areas exposed to higher intensity of human disturbance would show a greater patchiness in habitat mosaics and a greater proportion of degraded types of habitat (e.g. algal turfs or dead Posidonia oceanica matte). Second, focusing on rocky bottoms, we assessed the variability in the structure and composition of benthic communities along the human influence gradient. In particular, we tested the hypothesis that under more intense human pressures, species diversity would be lower, and small-scale spatial variability of assemblages would be altered.

\section{MATERIALS AND METHODS}

\section{Study locations}

An extensive survey was carried out along the coasts of Tuscany (NW Mediterranean Sea) in summer 2008. According to prevailing human activities, 4 levels of decreasing human pressure were identified: (1) urban reefs, (2) extra-urban reefs, (3) offshore reefs, and (4) MPAs off islands. Two locations were randomly selected for each of these conditions (Fig. 1).

Urban reefs were sampled in front of the cities of Livorno and Rosignano Solvay, which are located about $25 \mathrm{~km}$ apart along the coast of Tuscany and are considered pollution hotspots in European coastal waters (OECD 2002). Livorno has about 180000 inhabitants and hosts an oil refinery and one of the 


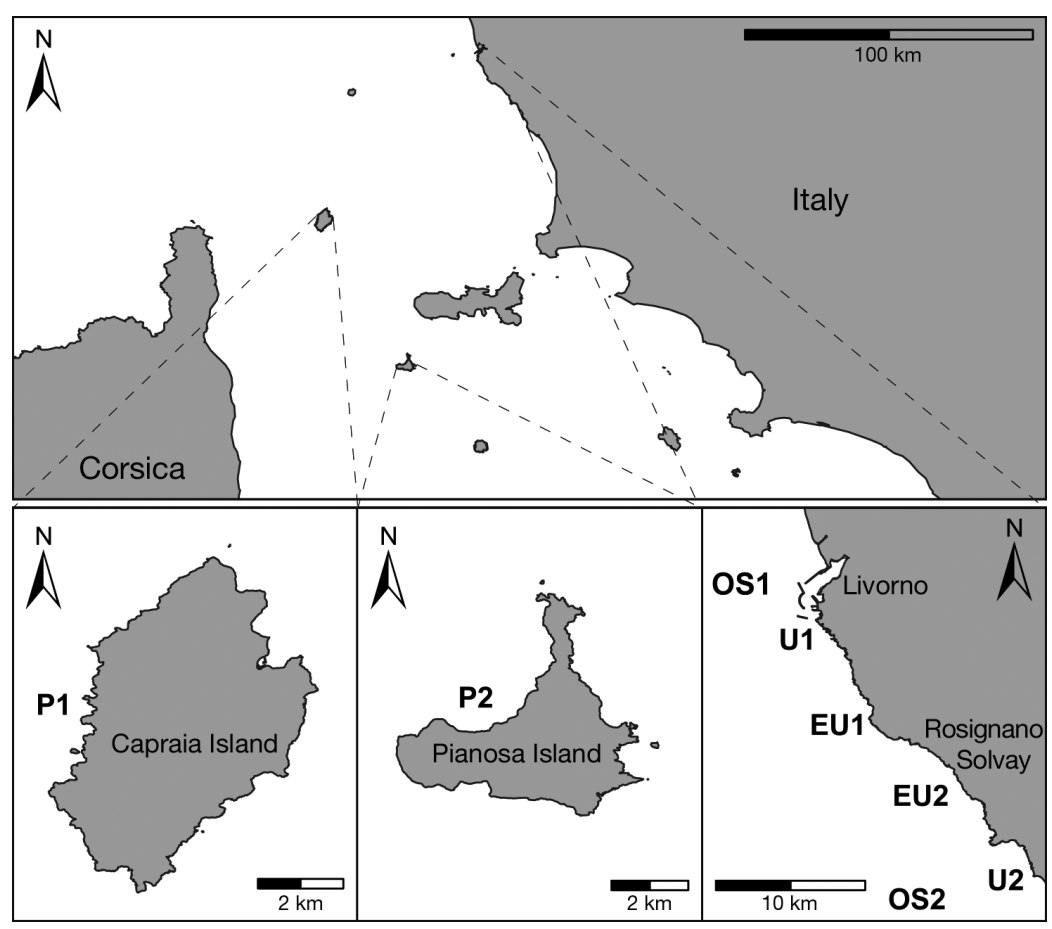

Fig. 1. Locations sampled in the NW Mediterranean: Capraia Island, Pianosa Island, and coast of Tuscany (left, central, and right panel, respectively). The 2 areas within each level of human influence locally available are indicated by capital letters. EU: extra-urban; OS: off-shore; P: protected; U: urban

ArcGIS and Marine Geospatial Ecology Tools (Roberts et al. 2010). Highresolution land use data $(100 \mathrm{~m}$ resolution) were obtained from the Corine Land Cover 2000 raster dataset version 15 (08/2011) provided by the European Topic Centre on Land Use and Spatial Information (ETC/LUSI). Descriptive categories were simplified into urban areas, industrial and port areas, agricultural, and natural areas. Estimates of population density in 2000 , at $1 \mathrm{~km}$ resolution, were extracted from the Global Rural Urban Mapping Project version 1 (GRUMPv1, http://sedac.ciesin.columbia.edu/data/ set/grump-v1-population-density), developed by the Columbia University Center for International Earth Science Information Network (CIESIN) in collaboration with the International Food Policy Research Institute (IFPRI), The World Bank, and Centro Internacional de Agricultura Tropical (CIAT) in 2011. Organic, nutrient, and inorganic pollution data, at $1 \mathrm{~km}$ resolution, were obtained from layers provided by

largest commercial ports of NW Italy. Rosignano Solvay is a smaller urban area, but industrial plants for the production of baking soda have been operating in the area since 1914.

Extra-urban areas were selected at least $8 \mathrm{~km}$ from main sources of pollution and disturbance. Human impacts due to run-off and inputs of organic and inorganic pollutants progressively decrease with increasing distance from the mainland, with a reduced influence on off-shore reefs (Secche della Meloria and Secche di Vada, 5.5 and $7.4 \mathrm{~km}$ from the coast, respectively) and nearly no effect off islands (Capraia and Pianosa, respectively 27.8 and $40.7 \mathrm{~km}$ from the coast). Off-shore reefs are characterized by intense boating and diving during summer months and by recreational and commercial fishing activities yearround. In contrast, human activities, such as fishing, boating, and anchoring, are totally banned from reefs sampled on the islands of Pianosa and Capraia (MPA included in the Tuscany Archipelago Natural Park).

In order to formally quantify human influences at a regional scale, we collected geographically referenced data of variables likely affecting shallow coastal ecosystems: land use, population density, and organic, nutrient, and inorganic pollution. Environmental data were elaborated and visualized using
Halpern et al. (2008). Scaled indices vary from 0 to 1 , with higher values representing increasing impact. Nutrients (fertilizers) and organic pollutants (pesticides) were modeled from data from the Food and Agriculture Organization (FAO) national statistics (http://faostat.fao.org) for the years 1993 to 2002 and 1992 to 2001, respectively. Non-point source inorganic pollution was modeled under the assumption that most of this pollution comes from urban runoff. The distance from land for which these layers were estimated varies depending on the nature of specific pollutants: no data were available for areas thought to be unaffected by organic and nutrient pollution (Capraia and Pianosa Islands).

The urban locations included in this study are densely populated (Fig. 2B; Livorno 1507.73 people $\mathrm{km}^{-2}$, Rosignano 341.33 people $\mathrm{km}^{-2}$ ), located in proximity to industrial or port areas (Fig. 2A) and exposed from high to maximum levels of organic (Fig. 2C), nutrient (Fig. 2D), and inorganic pollution (Fig. 2E). Extra-urban locations were selected in areas showing similar population densities (Fig. 2B), but lower urbanization, as shown by the proximity to natural areas in the land use map (Fig. 2A). Organic, nutrient, and inorganic pollution indices show lower values in extra-urban compared to urban locations 
(Fig. 2C-E). Off-shore reefs are exposed from high to medium levels of organic, nutrient, and inorganic pollution (Fig. 2C-E). In contrast, MPAs represent relatively pristine locations, with low population densities (Fig. 2G,L; Capraia 16.91 people $\mathrm{km}^{-2}$, Pianosa 48.71 people $\mathrm{km}^{-2}$ ) and the majority of the territory occupied by natural areas (Fig. 2F,K). Organic and nutrient pollution are nearly absent across the islands (Fig. 2H,I,M,N), while inorganic pollution levels are very low (pollution index $<0.006$; Fig. 2J,O).

\section{Sampling of habitat structure}

At each location, 8 transects of $30 \mathrm{~m}$ length and hundreds of meters apart, were randomly selected within an area of about $1 \mathrm{~km}^{2}$, at depths varying from 3 to $13 \mathrm{~m}$ (Fig. 1). Off islands, transects were selected on the west coast to allow comparisons with mainland lo- cations, in terms of geographical orientation and wave exposure. The relative proportion of different habitats was visually quantified by recording the habitats' linear extent and calculating their percentage cover along each transect. Seven habitat types could be identified according to the presence of dominant habitat formers or prevalent features of the substratum: (1) patches occupied by sand or gravel, (2) barren grounds (species-poor patches dominated by encrusting corallines and deprived of erect macroalgae), (3) precoralligenous assemblages (a hard substratum of biogenic origin that is mainly produced by the accumulation of calcareous encrusting algae growing in dim light conditions and hosting diverse macroalgae and invertebrates, (4) seagrass Posidonia oceanica meadows, (5) P. oceanica dead matte, (6) stands of canopyforming macroalgae (mostly Halopithys incurva and Cystoseira spp.), and (7) turf-forming macroalgae (mostly filamentous and articulated coralline forms).
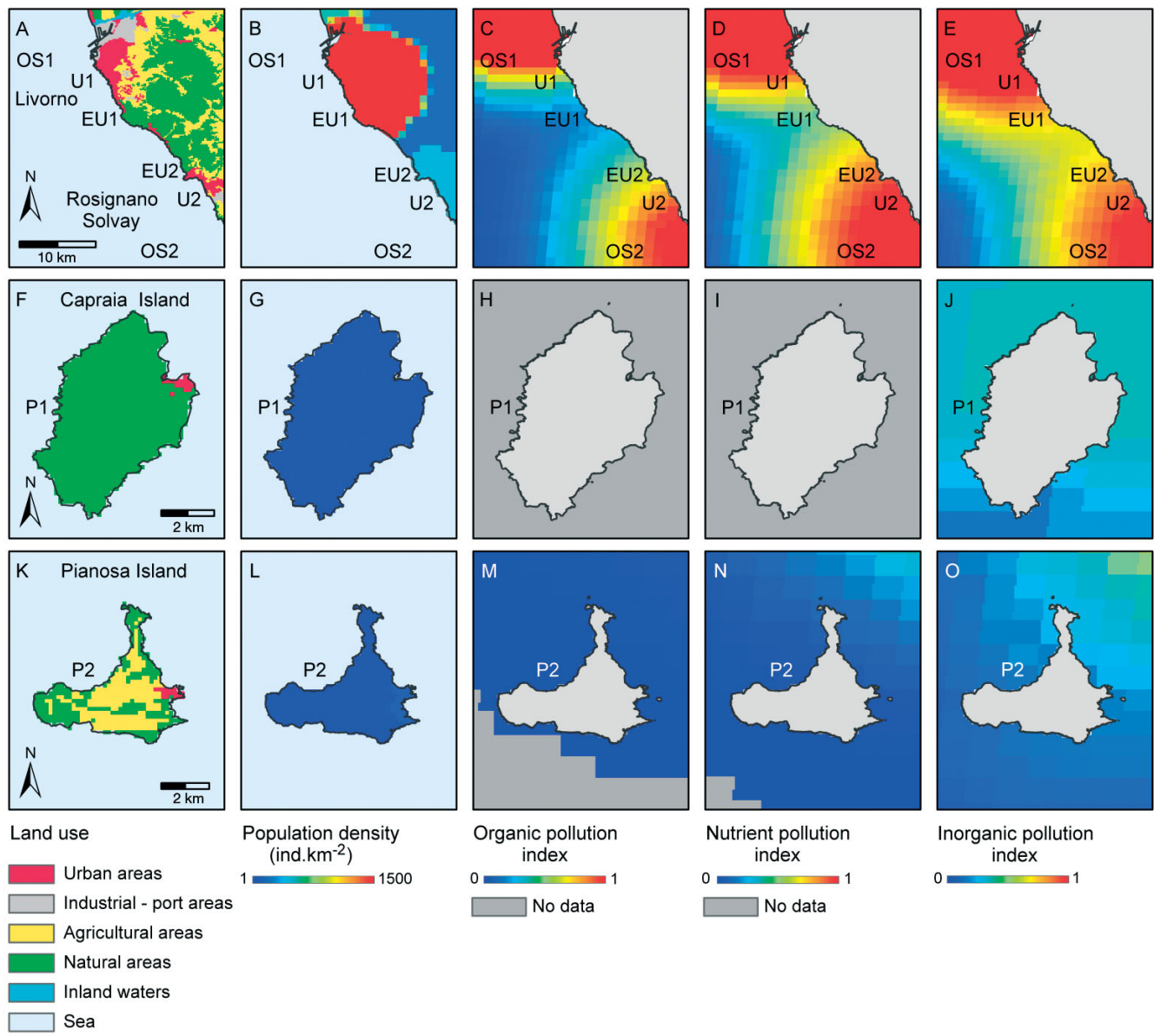
(ind. $\mathrm{km}^{-2}$ )

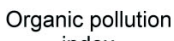
index
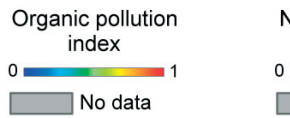

Nutrient pollution

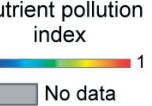

Inorganic pollution index

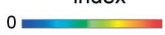

Fig. 2. Human influence in the study area, at locations (A-E) along the Tuscan coast, (F-J) on Capraia Island, and (K-O) on Pianosa Island. The 2 areas per level of human influence locally available are indicated by capital letters. EU: extra-urban; OS: off-shore; P: protected; U: urban. Shown are land use $(\mathrm{A}, \mathrm{F}, \mathrm{K})$; population density expressed as no. of inhabitants $\mathrm{km}^{-2}(\mathrm{~B}, \mathrm{G}, \mathrm{L})$, organic pollution index $(\mathrm{C}, \mathrm{H}, \mathrm{M})$, nutrient pollution index $(\mathrm{D}, \mathrm{I}, \mathrm{N})$, and inorganic pollution index $(\mathrm{E}, \mathrm{J}, \mathrm{O})$ with corresponding keys below each column of panels 
In order to examine patterns of variability in habitat distribution at the landscape scale, we calculated a contagion index (CI; Parresol 2011), which quantifies composition (i.e. number and relative proportions) and configuration (i.e. spatial arrangement and fragmentation) of different habitats along each transect. Each linear transect was divided into 300 cells of $10 \mathrm{~cm}$ length (our resolution for habitat mapping), and the CI was calculated as:

$$
\sum_{i=1}^{n} \sum_{j=1}^{n} \frac{P_{i j}^{2} \times \ln \left(P_{i j}\right)}{\left(P_{i j}-1\right)}
$$

where $n$ is the total number of habitat types in a particular transect, $P_{i j}$ is the product between the probability of a cell to be occupied by habitat $i\left(P_{i}\right)$ and the probability to be adjacent to a cell occupied by habitat $j\left(P_{i} P_{i j}\right)$. This CI is a function of an evenness index; it ranges from 0 to 1 and measures the extent to which patch types are aggregated or interspersed. Greater values of contagion occur in the presence of few large, contiguous patches, whereas many small and scattered patches generate lower values. In addition, we calculated mean patch size for each type of habitat and the global mean patch size among all habitats, in order to examine patterns of variability in habitat fragmentation (Zhang et al. 2011)

In order to account for potentially confounding effects due to substratum heterogeneity, we measured topographic complexity according to the chain method (Luckhurst \& Luckhurst 1978). One end of a $10 \mathrm{~m}$ long stainless-steel chain was randomly placed along the transect and allowed to sink to the bottom, while released in a straight line. Care was taken to ensure that the chain conformed to the contour of the substratum. The relative difference between the real length of the chain and the measured distance between the 2 ends when conforming to the substratum provides a good estimate of complexity. This quantity was divided by the original length of the chain, in order to obtain values ranging from 0 to 1 , with smaller values indicating increasing complexity. Two measures of complexity were taken along each transect and subsequently averaged, to be included in multivariate analysis as a covariate.

\section{Sampling of rocky reef assemblages}

At each location, a minimum of 5 transects were placed entirely on rocky substrata. Thus, at each location, the structure of rocky benthic assemblages was quantified in 6 quadrats $(20 \times 15 \mathrm{~cm})$ randomly placed along 5 transects. Five transects were randomly selected at locations where a greater proportion of transects lying on rocky substrata was available. Quadrats were photographed by divers using a digital camera (Canon PowerShot S70) equipped with a waterproof case and a metal spacer (28 cm long) and framer. When present, canopy-forming macroalgae were set aside to take pictures of understory assemblages. The percentage cover of macroalgae and sessile invertebrates was visually estimated on a PC screen. A grid of 25 sub-quadrats was superimposed onto each image, a score from 0 to $4 \%$ was given to each taxon in each subquadrat, and the percentage cover was obtained by summing over the entire set of subquadrats. Sessile invertebrates, which represented $1.044 \pm 0.138 \%$ (mean \pm SE per plot), were sampled estimating their percentage cover and not the number of individuals, as they were mainly (75\%) composed of encrusting and/or colonial organisms (e.g. sponges, bryozoans, didemnids, encrusting vermetids). Organisms could generally be identified to the species level, except for encrusting and filamentous algal forms, which were treated as morphological groups.

\section{Statistical analyses}

\section{Habitat structure}

The relative proportion and the mean patch size of each habitat type, the global average patch size and the CI were analyzed by means of 2-factor analyses of variance (ANOVAs), including the Condition (fixed, with 4 levels: Urban, Extra-Urban, Off-shore, MPA) and the Location (random, with 2 levels, nested within Condition). Cochran's $C$-test was used before each analysis to check for homogeneity of variance, and data were $\ln (x+1)$ transformed when necessary (Underwood 1997). The data were analyzed even when homogeneity of variance was not achieved by transformation, since ANOVA is robust for the departure from this assumption when there are many independent replicates $(n=64)$ and sizes of samples are equal. When necessary, pooling procedures were applied according to Underwood (1997). StudentNewman-Keuls (SNK) tests were used for a posteriori comparisons of the means. The analysis was also repeated for a second, less conservative CI (CI2) proposed by Parresol (2011), which is calculated as:

$$
\sum_{i=1}^{n} \sum_{j=1}^{n}\left[P_{i j} \times \ln \left(P_{i j}\right)\right]
$$

The results did not differ from those obtained for CI and are therefore not reported. 


\section{Structure of rocky reef assemblages}

Differences in the structure of rocky benthic assemblages among areas subjected to different human influences were tested by means of a permutational multivariate analysis of variance (PERMANOVA; Anderson 2001) performed on a BrayCurtis dissimilarity matrix of untransformed data. The model included 3 factors: Condition (fixed, with 4 levels: Urban, Extra-Urban, Off-shore, MPA), Location (random, nested within Condition, with 2 levels) and Transect (random, nested within Location, with 5 levels), and substratum heterogeneity as a covariate. The same analysis was repeated also including the depth of each plot as a covariate. Since depth did not significantly contribute to explain variability in assemblage structure, the analysis is not reported. Permutational analysis of multivariate dispersion (PERMDISP, Anderson 2006) and pairwise a posteriori comparisons were performed to evaluate whether differences among conditions were due to diverse dispersion and, hence, heterogeneity of assemblages. Multivariate patterns were displayed by plotting centroids of each transect in a 2-dimensional non-metric multidimensional scaling (nMDS) plot.

Percent cover of the most abundant species or morphological groups (classified according to Steneck \& Dethier 1994), species richness (number of taxa) and evenness (calculated as the reciprocal of Simpson's index/number of species) of assemblages were analyzed using a 3-factor ANOVA, with the same design described for PERMANOVA.

\section{RESULTS}

\section{Habitat structure}

Stands of canopy-forming macroalgae were nearly absent in urban, extra-urban, and off-shore reefs, while they represented the dominant habitat in MPAs (Table 1, Fig. 3f). In accordance, the availability of habitats formed by turfing macroalgae was significantly lower in MPAs than off the mainland (i.e. urban and extra-urban) or on off-shore reefs (Table 1 , Fig. 3g). The ANOVA showed significant differences between conditions in the availability of Posidonia oceanica beds and dead matte, but the SNK tests could not rank the means (Table 1, Fig. 3D,E). There was, however, a trend for a greater extension of $P$. oceanica beds and dead matte on off-shore and urban reefs, respectively (Fig. 3d,e).
The relative proportions of coralligenous, barren, and sandy habitats (Table 1, Fig. 3a-c), as well as the spatial configuration of habitats (estimated through the CI) and the global mean patch size did not vary among conditions (Tables $1 \& 2$ ). In contrast, the degree of fragmentation of coralligenous, dead matte, and macroalgal canopy habitats (estimated as the mean patch size) significantly varied among conditions (Table 2). Patches dominated by coralligenous and macroalgal canopy were significantly larger in MPAs than in other conditions (Table 2, Fig. 4), while the SNK test failed to provide an alternative to the null hypothesis for dead matte. Mean patch size of barrens, algal turfs, Posidonia oceanica beds, and sandy habitats did not vary among conditions (Table 2).

\section{Structure of rocky reef assemblages}

After accounting for the variability due to topographic complexity, the structure of rocky reef assemblages differed among conditions, locations, and transects (Table 3, Fig. 5). In addition, the PERMDISP analysis showed significant differences among conditions in terms of dispersion and, hence, in small-scale variability of assemblages (Table 3 ). Variability among replicates was greatest in MPAs and progressively decreased along the gradient of human influence, with assemblages of urban areas being more homogeneous (Fig. 5).

There was no effect of the level of human influence on the diversity or evenness of benthic assemblages (Table 4). In accordance to patterns of habitat availability, Cystoseira spp. dominated space in MPAs, while they were scarcely abundant in off-shore areas and absent off the mainland (Table 4, Fig. 6a). Peyssonnelia spp. were more abundant in MPAs than in all other conditions of human influence (Table 4, Fig. 6c). In contrast, the percentage cover of filamentous algae was greater on reefs off the mainland (e.g. urban and extra-urban) than in off-shore or MPA reefs (Fig. 6b). The ANOVA did not detect significant differences in the cover of articulate and encrusting coralline macroalgae (Table 4).

\section{DISCUSSION}

Only a few habitat types (coralligenous, dead matte, and canopy stands) varied in terms of habitat fragmentation among areas exposed to different human influences, and there were no significant dif- 

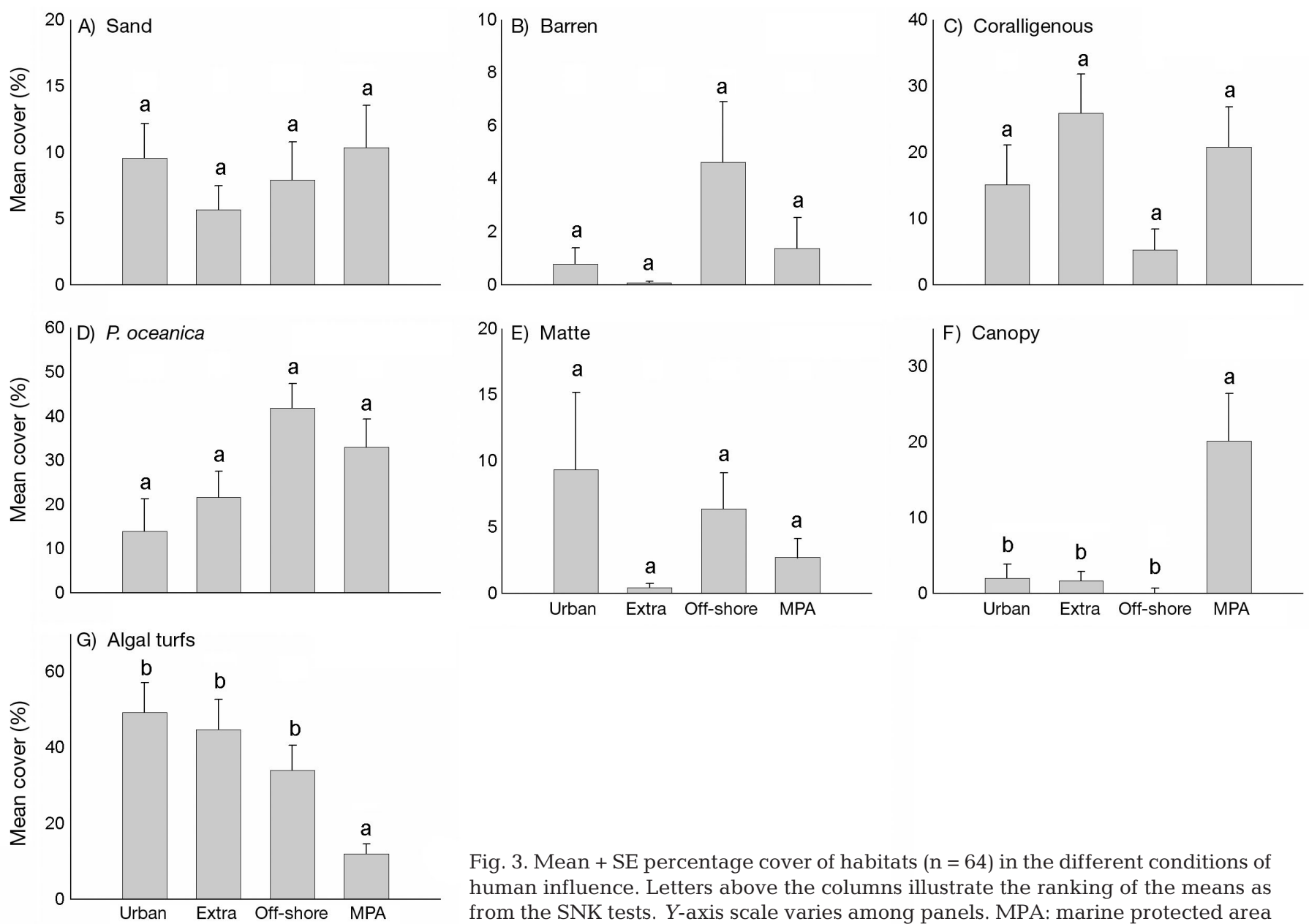

Fig. 3. Mean + SE percentage cover of habitats $(n=64)$ in the different conditions of human influence. Letters above the columns illustrate the ranking of the means as from the SNK tests. $Y$-axis scale varies among panels. MPA: marine protected area

ferences in the extent to which habitat patches are aggregated or interspersed. The scarce evidence of fragmentation suggests that the characteristics of prevailing human activities do not necessarily result in smaller and more interspersed patches of habitats, as demonstrated by other studies (Boström et al. 2011). This could be due to the fact that heterogeneity in the spatial arrangement of habitat patches can be a natural feature of shallow reefs. Habitat diversity and fragmentation can, in fact, be generated by natural processes like grazing or the hydrodynamic regime (Bell et al. 1999 and references therein) or by physical features of the bottom, such as topographic complexity or the alternation of sedimentary and rocky substrata.

Rather, human influence could determine gradual changes in habitat composition when moving from urban through extra-urban areas to off-shore banks, while generating a more abrupt shift between these 3 continental areas and islands. For instance, habitats formed by algal canopies (Cystoseira spp.) were found nearly exclusively on island MPA reefs, and, not surprisingly, mean patch size of this habitat type was larger there than at other locations where canopyformers were sparsely present. Loss of Cystoseira spp. canopies is strongly correlated with urbanization (Benedetti-Cecchi et al. 2001, Mangialajo et al. 2008, Sales \& Ballesteros 2009). The decline of these macroalgae can, in fact, be promoted by eutrophication (Soltan et al. 2001), increase in water turbidity, and sedimentation (Airoldi \& Beck 2007).

Factors such as orientation and wave exposure can influence patterns of distribution of Cystoseira spp. (Sales \& Ballesteros 2009). However, they likely played only a small role in determining regional variations in the abundance of these macroalgae, since sampling was carried out at locations with similar orientation and hydrodynamic conditions. Indeed, the presence of Cystoseira spp. has been historically documented along the Tuscan coast (Cinelli 1969), suggesting a case of habitat loss. In other regions of the Mediterranean Sea, the genus Cystoseira is still pre- 
sent in moderately or scarcely urbanized areas (Mangialajo et al. 2008). The decline of Cystoseira spp. has been far more dramatic in our study region, where these species have completely disappeared from mainland reefs, and a few scattered individuals can be occasionally found on off-shore reefs that, similar to the mainland reefs, are characterized by poor water quality. The canopy-forming macroalga Halopithys incurva is relatively resistant to anthropogenic disturbance (e.g. sedimentation, Bulleri et al. 2010), but densities were too low to form a distinct habitat on urban and extra-urban reefs.

When comparing the relative proportions of habitat types on rocky bottoms (i.e. excluding transects lying entirely on Posidonia oceanica beds or sandy areas), stands of algal turfs represented the dominant habitat in coastal areas, with covers up to $90 \%$ in urban,

Table 3. Permutational multivariate analysis of variance (PERMANOVA), permutational analysis of multivariate dispersion (PERMDISP), and a posteriori comparisons between different conditions of human influence on benthic assemblages of rocky reefs, after accounting for substratum heterogeneity as a covariate. MPA: marine protected area

\begin{tabular}{|c|c|c|c|c|}
\hline Source of variation & df & MS & Pseudo- $F$ & $\mathrm{p}$ \\
\hline Covariate & 1 & $11107^{\mathrm{a}}$ & 2.961 & 0.012 \\
\hline Condition $=\mathrm{C}$ & 3 & $30116^{\mathrm{b}}$ & 5.433 & 0.001 \\
\hline Location = Lo(C) & 4 & $5596.9^{\mathrm{c}}$ & 2.015 & 0.003 \\
\hline Transect $=\operatorname{Tr}(\operatorname{Lo}(\mathrm{C}))$ & 31 & $2777.8^{\mathrm{d}}$ & 3.236 & 0.001 \\
\hline Residual = Res & 200 & 858.29 & & \\
\hline Total & 239 & & & \\
\hline \multicolumn{3}{|c|}{ Pairwise test between conditions } & $t$ & $\mathrm{p}$ \\
\hline \multicolumn{3}{|l|}{ Urban, Extra-urban } & 2.1964 & 0.004 \\
\hline \multicolumn{3}{|l|}{ Urban, Off-shore } & 3.2598 & 0.003 \\
\hline \multicolumn{3}{|l|}{ Urban, MPA } & 3.1838 & 0.002 \\
\hline \multicolumn{3}{|l|}{ Extra-urban, Off-shore } & 1.7164 & 0.041 \\
\hline \multicolumn{3}{|l|}{ Extra-urban, MPA } & 2.3051 & 0.012 \\
\hline \multicolumn{3}{|l|}{ Off-shore, MPA } & 1.8153 & 0.035 \\
\hline \multicolumn{3}{|c|}{ Deviations from centroid } & Pseudo- $F$ & $\mathrm{p}$ \\
\hline \multicolumn{3}{|l|}{ Condition } & 51.037 & 0.001 \\
\hline \multicolumn{4}{|c|}{ Pairwise test of deviation from } & $\mathrm{p}$ \\
\hline \multicolumn{3}{|l|}{ Urban, Extra-u } & 5.9427 & 0.001 \\
\hline \multicolumn{3}{|l|}{ Urban, Off-shore } & 8.4496 & 0.001 \\
\hline \multicolumn{3}{|l|}{ Urban, MPA } & 13.348 & 0.001 \\
\hline \multicolumn{3}{|l|}{ Extra-urban, Off-shore } & 2.6122 & 0.022 \\
\hline \multicolumn{3}{|l|}{ Extra-urban, MPA } & 6.3624 & 0.001 \\
\hline \multicolumn{3}{|l|}{ Off-shore, MPA } & 3.319 & 0.002 \\
\hline \multicolumn{5}{|c|}{$\begin{array}{l}\text { a Denominator }=0.345 \operatorname{Lo}(C)+0.655 \operatorname{Tr}(\operatorname{Lo}(C))+0.007 \text { Res, } \\
{ }^{b} \text { Denominator }=0.981 \operatorname{Lo}(C)+0.019 \operatorname{Tr}(\operatorname{Lo}(C)) \\
{ }^{c} \text { Denominator }=\operatorname{Tr}(\operatorname{Lo}(C)) \\
\text { d Denominator }=\operatorname{Res}\end{array}$} \\
\hline
\end{tabular}



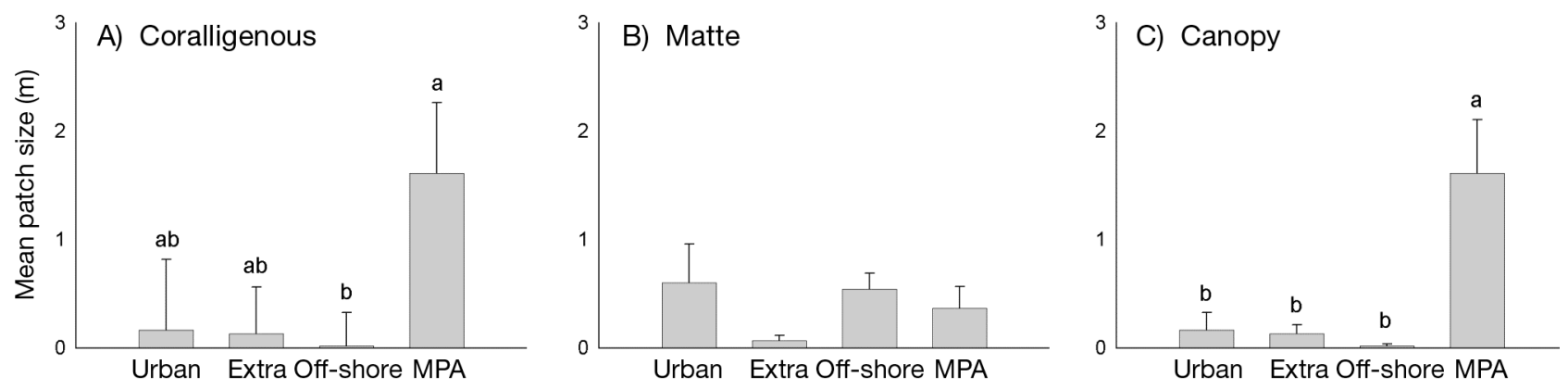

Fig. 4. Mean + SE patch size of habitats $(n=64)$ in the different conditions of human influence. Letters above the columns illustrate the ranking of the means as from the SNK tests. MPA: marine protected area

extra-urban, and off-shore reefs. In contrast, they represented only a small proportion of habitat $(<30 \%$ cover) in off-island MPAs. Dominance of algal turfs is positively correlated with poor water quality due to coastal runoff, increasing sedimentation, and nutrient loads (Gorgula \& Connell 2004). Our results suggest that land-based human activities have the potential to alter the structure of algal assemblages also on reefs several kilometers off the coast.

There is a global trend for a decline and loss of seagrass beds along continental coasts, as a consequence of mechanical damage (e.g. trawling or anchoring) and poor water quality (Duarte 2002, Airoldi \& Beck 2007). Seagrass bed regression and disappearance generally occur over temporal scales of tens to hundreds of years (Airoldi \& Beck 2007) and can hardly be documented by short-term studies. However, a considerable decline of this habitat along the coast of Tuscany emerges clearly from the comparison of maps of Posidonia oceanica beds produced in 1990 and 2009 (Padovani 2009). This would suggest that the smaller extension of seagrass beds on mainland than off-shore or island reefs, documented by this study, would not reflect natural variation in the distribution of this habitat-forming plant, but rather variations in the intensity of human disturbance across the region.

In addition, our results suggest that the loss of seagrass meadows and the increase in the extent of dead matte patches do not necessarily occur under the same type and intensity of human pressures. For instance, off-shore banks are characterized by extensive Posidonia oceanica beds, being probably less influenced by land-based human activities than coastal reefs. However, greater cover and larger average patch size of dead matte in these areas compared to extra-urban areas likely reflect detrimental effects of recreational boating and artisanal fishing activities (e.g. anchoring, entanglement of nets) that can be more severe here than on coastal reefs.
In contrast to our expectation, the distribution of encrusting coralline barrens did not vary according to prevailing human influences. Barren habitats are common in overfished areas, where a reduced predatory pressure causes an increase in urchin density and, ultimately, overconsumption of erect macroalgae (Guidetti 2006). Therefore, we expected a lower extent of barren habitats within island MPAs, although previous studies did not detect a direct correlation between barren cover and protection regime at these sites (e.g. Micheli et al. 2005). The lack of shift towards canopy-dominated habitats has been recognized as a common phenomenon in poorly enforced protected areas (Guidetti et al. 2008). At all our study locations, patches of encrusting corallines represented a small fraction of total habitat (average cover $<5 \%$ ) and presented a small average size $(0.96 \pm 0.12 \mathrm{~m})$. Thus, variation in natural processes, such as wave exposure (Micheli et al. 2005) and recruitment rates (Behrens \& Lafferty 2004), might be

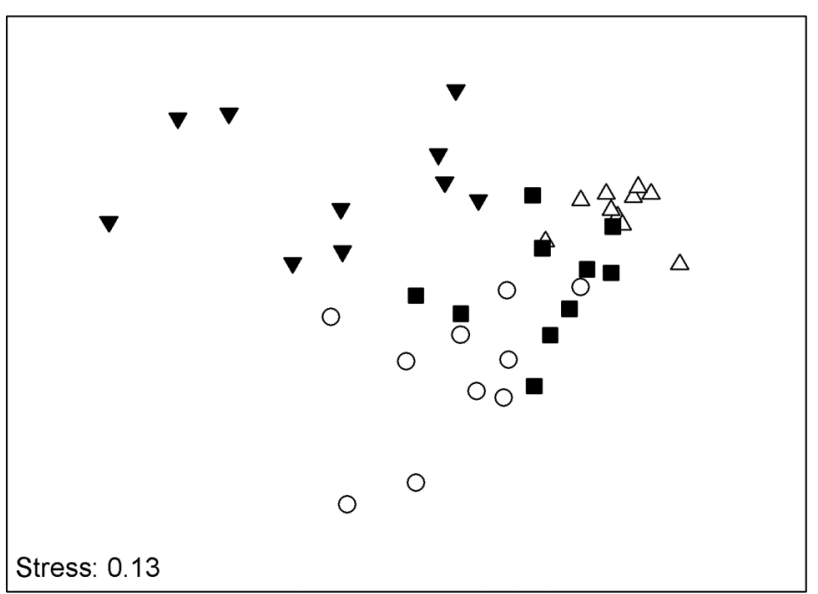

Fig. 5. Non-metric multidimensional scaling plot of benthic assemblages on rocky reefs representing centroids for each transect across different conditions of human influence. $\Delta$ : urban reefs, $\mathbf{\square}$ : extra-urban reefs, O: off-shore reefs, $\nabla$ : marine protected areas 


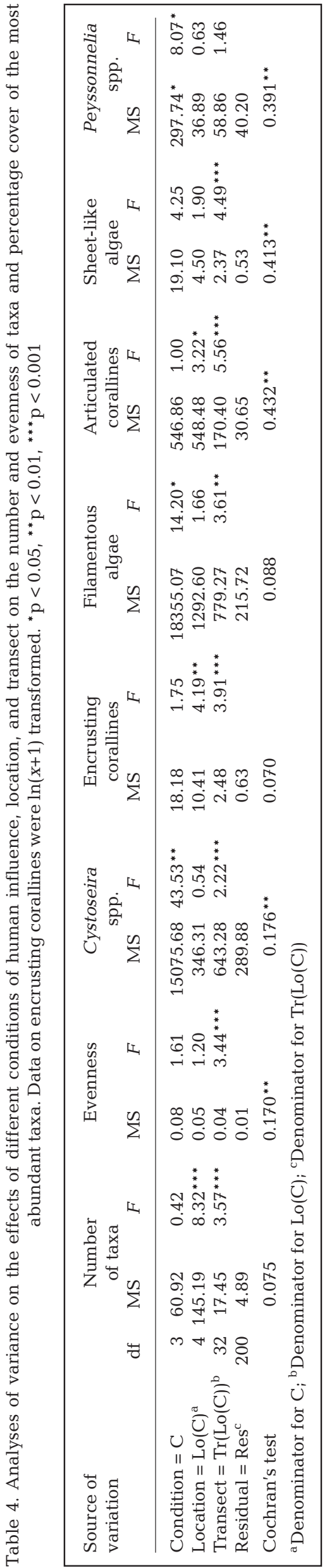

more important than prevailing human influences in determining the extent of coralline barrens.

Finally, the extent of coralligenous formations did not vary among areas exposed to different human influences. This is in accordance with the findings of Piazzi et al. (2004), who found no differences in coralligenous assemblages among coastal, off-shore, and island reefs at depths greater than those encompassed by our study. These patterns are unexpected, since coralligenous assemblages have been shown to be susceptible to several kinds of human disturbances (i.e. nutrient enrichment: Hong 1983; sediment deposition: Balata et al. 2005; trawling: Palanques et al. 2001; recreational diving: Coma et al. 2004).

Coralligenous habitats were, however, more fragmented in coastal areas and off-shore reefs than off islands. At shallow depths like those encompassed by our study, coralligenous formations are mainly composed of green macroalgae (like Halimeda tuna or Flabellia petiolata) and articulated or encrusting corallinales, with a smaller component of sessile invertebrates (on average $<1.5 \%$ per plot) that generally become dominant at greater depths (Ballesteros 2006). Human disturbances could further favor the dominance of macroalgae given their greater tolerance to stress in comparison to sessile invertebrates (Airoldi \& Virgilio 1998, Benedetti-Cecchi et al. 2001).

In general, the structure of rocky benthic communities markedly differed among areas subjected to different human influences. Species more susceptible to the degradation of environmental conditions (e.g. Cystoseira spp. and Peyssonnelia spp.) were dominant off islands (Soltan et al. 2001). In contrast, filamentous algae flourished in coastal areas, likely by virtue of their ability to conquer and retain space under enhanced sediment and nutrient loads (Airoldi \& Virgilio 1998, Gorgula \& Connell 2004). Our coarse taxonomical resolution for filamentous species, however, does not allow us to assess whether filamentous algal assemblages differed in species composition along the gradient of disturbances examined). Finally, some algal groups (i.e. articulated and encrusting corallines or sheet-like algae) did not vary along the gradient of disturbances. Articulated and encrusting corallines tolerate stressful conditions (Airoldi \& Virgilio 1998).

Small-scale variability was greatest on island reefs and decreased along the gradient of human influence, with assemblages off urban areas displaying the greatest homogeneity. Reduction in small-scale variability has been identified as an outcome of 

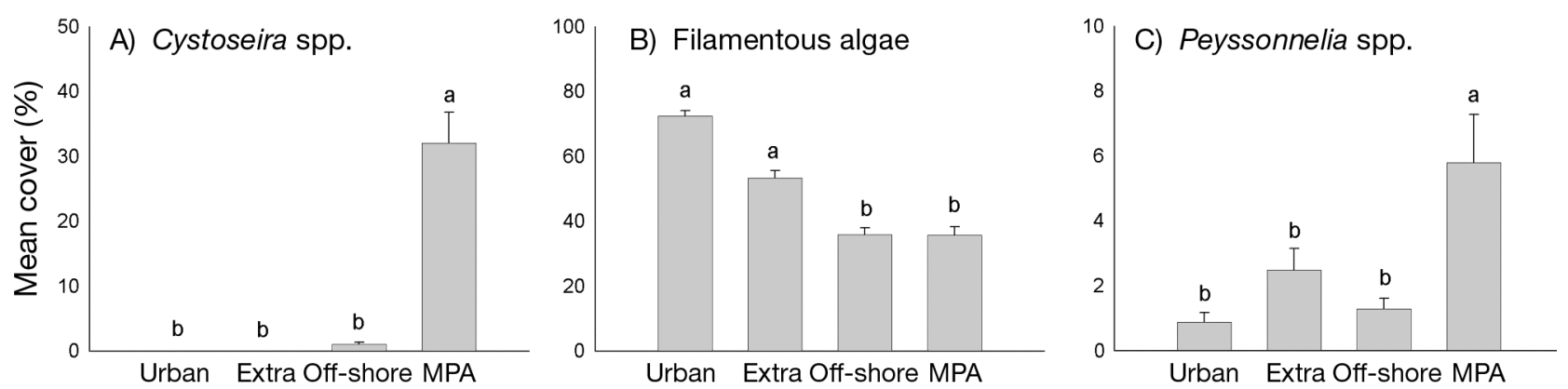

Fig. 6. Mean + SE percentage cover of more abundant taxonomical or morphological groups $(n=240)$ in the different conditions of human influence. Letters above the columns illustrate the ranking of the means as from the SNK tests. $Y$-axis scale varies among panels. MPA: marine protected area

chronic human influences (Chapman et al. 1995). Such homogenization did not, however, correspond to a reduction in species diversity or evenness. Biotic homogenization can in fact be paralleled by an increase in local diversity as a result of the replacement of vulnerable species by others that are more disturbance-tolerant (Abadie et al. 2011). Vulnerable species tend to be habitat specialists, while disturbance-tolerant species are often habitat generalists, thus resulting in the biotic homogenization of assemblages at a small scale (Abadie et al. 2011).

In summary, our assessment of human impacts at different levels of ecological complexity has disclosed similar responses at the landscape and at the assemblage scale, suggesting that disturbances might favor the shift to degraded assemblages through the displacement of habitat-forming species. Although supported by historical and contemporary literature and by the mapping of habitats and human pressures, our work is purely correlative. Descriptive studies over regional scales have the merit to depict complex patterns of variability along a gradient of multiple human pressures, but it is important to bear in mind that the correlative approach does not allow us to identify cause and effect relationships. Experimental studies can provide insight into the effects of multiple stressors (Crain et al. 2008), but due to logistic constraints, they are often limited to simplified settings (laboratory or mesocosms) and focused on the response of single species (Crain et al. 2008). Even more rarely, the experimental approach has been applied to investigate the effects of habitat loss or fragmentation on biota homogenization (Boström et al. 2011) or ecosystem functioning (Bulling et al. 2008, Godbold et al. 2011).

Previous studies suggested that habitats represent an efficient proxy to quantify biodiversity, especially over broad scales (Ward et al. 1999). Having to choose a set of representative sites for a marine reserve network, Ward et al. (1999) compared investigations at the habitat and assemblage scale in a pristine region. Their findings suggest that habitat categories can efficiently be used to identify highpriority areas deserving protection. Our study supports the conclusions of Ward et al. (1999), showing that focusing on habitat categories can provide reliable estimates of the effects of multiple human influences and can provide information for management strategies over regional scales.

Acknowledgements. We sincerely thank I. Bertocci and C. Cristaudo for help with fieldwork. We thank the Duke University Marine Geospatial Ecology Lab for providing computational resources used in this study. The research leading to these results has received funding from the University of Pisa through the project Bioclima, the MIUR through the project BIORES and from the European Community's Seventh Framework Programme (FP7/2007-2013) under Grant Agreement No. 266445 for the project Vectors of Change in Oceans and Seas Marine Life, Impact on Economic Sectors (VECTORS). Many thanks to G. Fissore (Assonautica Livorno) for assisting with boating operations. While writing, F.B. was supported by funds from an Assegno di Ricerca from the University of Sassari.

\section{LITERATURE CITED}

Abadie JC, Machon N, Muratet A, Porcher E (2011) Landscape disturbance causes small-scale functional homogenization, but limited taxonomic homogenization, in plant communities. J Ecol 99:1134-1142

Airoldi L, Beck MW (2007) Loss, status and trends for coastal marine habitats of Europe. Oceanogr Mar Biol Annu Rev 45:345-405

Airoldi L, Virgilio M (1998) Responses of turf-forming algae to spatial variations in the deposition of sediments. Mar Ecol Prog Ser 165:271-282

Anderson MJ (2001) A new method for non-parametric multivariate analysis of variance. Austral Ecol 26:32-46

Anderson MJ (2006) Distance-based tests for homogeneity of multivariate dispersion. Biometrics 62:245-253

Balata D, Piazzi L, Cecchi E, Cinelli F (2005) Variability of Mediterranean coralligenous assemblages subject to 
local variation in sediment deposition. Mar Environ Res 60:403-421

Balestri E, Benedetti-Cecchi L, Lardicci C (2004) Variability in patterns of growth and morphology of Posidonia oceanica exposed to urban and industrial wastes: contrasts with two reference locations. J Exp Mar Biol Ecol 308:1-21

Ballesteros E (2006) Mediterranean coralligenous assemblages: a synthesis of present knowledge. Oceanogr Mar Biol Annu Rev 44:123-195

Behrens MD, Lafferty KD (2004) Effects of marine reserves and urchin disease on southern Californian rocky reef communities. Mar Ecol Prog Ser 279:129-139

Bell SS, Robbins BD, Jensen SL (1999) Gap dynamics in a seagrass landscape. Ecosystems 2:493-504

Benedetti-Cecchi L, Pannacciulli F, Bulleri F, Moschella PS, Airoldi L, Relini G, Cinelli F (2001) Predicting the consequences of anthropogenic disturbance: large-scale effects of loss of canopy algae on rocky shores. Mar Ecol Prog Ser 214:137-150

Boström C, Pittman SJ, Simenstad C, Kneib RT (2011) Seascape ecology of coastal biogenic habitats: advances, gaps, and challenges. Mar Ecol Prog Ser 427:191-217

Bulleri F, Benedetti-Cecchi L, Acunto S, Cinelli F, Hawkins SJ (2002a) The influence of canopy algae on vertical patterns of distribution of low-shore assemblages on rocky coasts in the northwest Mediterranean. J Exp Mar Biol Ecol 267:89-106

Bulleri F, Bertocci I, Micheli F (2002b) Interplay of encrusting coralline algae and sea urchins in maintaining alternative habitats. Mar Ecol Prog Ser 243:101-109

Bulleri F, Balata D, Bertocci I, Tamburello L, BenedettiCecchi L (2010) The seaweed Caulerpa racemosa on Mediterranean rocky reefs: from passenger to driver of ecological change. Ecology 91:2205-2212

Bulling MT, Solan M, Dyson KE, Hernandez-Milian G and others (2008) Species effects on ecosystem processes are modified by faunal responses to habitat composition. Oecologia 158:511-520

> Chapman MG, Underwood AJ, Skilleter GA (1995) Variability at different spatial scales between a subtidal assemblage exposed to the discharge of sewage and two control assemblages. J Exp Mar Biol Ecol 189:103-122

Cinelli F (1969) Primo contributo alla conoscenza della vegetazione algale bentonica del litorale di Livorno. Pubbl Stn Zool Napoli 37:545-566

> Claudet J, Fraschetti S (2010) Human-driven impacts on marine habitats: a regional meta-analysis in the Mediterranean Sea. Biol Conserv 143:2195-2206

> Coma R, Polà E, Ribes M, Zabala M (2004) Long-term assessment of temperate octocoral mortality patterns, protected vs. unprotected areas. Ecol Appl 14: 1466-1478

Crain CM, Kroeker K, Halpern BS (2008) Interactive and cumulative effects of multiple human stressors in marine systems. Ecol Lett 11:1304-1315

Duarte CM (2002) The future of seagrass meadows. Environ Conserv 29:192-206

Godbold JA, Bulling MT, Solan M (2011) Habitat structure mediates biodiversity effects on ecosystem properties. Proc R Soc Lond B Biol Sci 278:2510-2518

Gorgula SK, Connell SD (2004) Expansive covers of turfforming algae on human-dominated coast: the relative effects of increasing nutrient and sediment loads. Mar Biol 145:613-619
Gorman D, Connell SD (2009) Recovering subtidal forests in human-dominated landscapes. J Appl Ecol 46: 1258-1265

Gray JS (1997) Marine biodiversity: patterns, threats and conservation needs. Biodivers Conserv 6:153-157

Guidetti P (2006) Marine reserves reestablish lost predatory interactions and cause community changes in rocky reefs. Ecol Appl 16:963-976

Guidetti P, Milazzo M, Bussotti S, Molinari A and others (2008) Italian marine reserve effectiveness: Does enforcement matter? Biol Conserv 141:699-709

Halpern BS, Selkoe KA, Micheli F, Kappel CV (2007) Evaluating and ranking the vulnerability of global marine ecosystems to anthropogenic threats. Conserv Biol 21: 1301-1315

Halpern BS, Walbridge S, Selkoe KA, Kappel CV and others (2008) A global map of human impact on marine ecosystems. Science 319:948-952

Hong JS (1983) Impact of pollution on the benthic community. Environmental impact of the pollution on the benthic coralligenous community in the Gulf of Fos, northwestern Mediterranean. Bull Korean Fish Soc 16:273-290

> Luckhurst BE, Luckhurst K (1978) Analysis of the influence of substrate variables on coral reef fish communities. Mar Biol 49:317-323

Mangialajo L, Chiantore M, Cattaneo-Vietti R (2008) Loss of fucoid algae along a gradient of urbanisation, and structure of benthic assemblages. Mar Ecol Prog Ser 358: 63-74

Micheli F, Benedetti-Cecchi L, Gambaccini S, Berocci I, Borsini C, Osio GC, Romani F (2005) Cascading human impacts, marine protected areas, and the structure of Mediterranean reef assemblages. Ecol Monogr 75:81-102

OECD (Organisation for Economic Co-operation and Development) (2002) OECD environmental performance reviews: Italy 2002. OECD Publishing, Paris

Padovani S (2009) Relazione tecnica per l'esecuzione di una campagna di rilievi morfologici per la mappatura della Posidonia in due aree della regione Toscana una a sud di Livorno ed una a nord di Piombino. Available at www.gionha.it/risorse/pubblicazioni/report/monitoraggioposidonia-relazione-tecnica.zip/view (accessed 10 February 2012)

Palanques A, Guillén J, Puig P (2001) Impact of bottom trawling on water turbidity and muddy sediment of an unfished continental shelf. Limnol Oceanogr 46: 1100-1110

> Parresol BR (2011) Derivation of two well-behaved theoretical contagion indices and their sampling properties and application for assessing forest landscape diversity. Nat Resour Model 24:61-101

Piazzi L, Balata D, Pertusati M, Cinelli F (2004) Spatial and temporal variability of Mediterranean macroalgal coralligenous assemblages in relation to habitat and substratum inclination. Bot Mar 47:105-115

> Roberts JJ, Best BD, Dunn DC, Treml EA, Halpin PN (2010) Marine geospatial ecology tools: an integrated framework for ecological geoprocessing with ArcGIS, Python, R, MATLAB, and C plus. Environ Model Softw 25: 1197-1207

> Sales M, Ballesteros E (2009) Shallow Cystoseira (Fucales: Ochrophyta) assemblages thriving in sheltered areas from Menorca (NW Mediterranean): relationships with environmental factors and anthropogenic pressures. Estuar Coast Shelf Sci 84:476-482 
Soltan D, Verlaque M, Boudouresque CF, Francour P (2001) Changes in macroalgal communities in the vicinity of a Mediterranean sewage outfall after the setting up of a treatment plant. Mar Pollut Bull 42:59-70

Steneck RS, Dethier MN (1994) A functional group approach to the structure of algal-dominated communities. Oikos 69:476-498

Underwood AJ (1997) Experiments in ecology: their logical design and interpretation using analysis of variance. Cambridge University Press, Cambridge

Editorial responsibility: Martin Solan,

Southampton, UK
Ward TJ, Vanderklift MA, Nicholls AO, Kenchington RA (1999) Selecting marine reserves using habitats and species assemblages as surrogates for biological diversity. Ecol Appl 9:691-698

Warwick RM, Clarke KR (1993) Increased variability as a symptom of stress in marine communities. J Exp Mar Biol Ecol 172:215-226

Zhang Y, Zhaoning G, Huili G, Wenji Z (2011) Investigating the dynamics of wetland landscape pattern in Beijing from 1984 to 2008. J Geogr Sci 21:845-858

Submitted: November 4, 2011; Accepted: March 5, 2012 Proofs received from author(s): June 4, 2012 